\title{
What are patients' expectations about the organization of their primary care physicians' practices?
}

\author{
Paul Sebo ${ }^{1 *}$, François R. Herrmann², Patrick Bovier ${ }^{3}$ and Dagmar M. Haller ${ }^{4,5,6}$
}

\begin{abstract}
Background: To our knowledge no study has at the same time assessed patients' satisfaction and their expectations concerning the organizational and contextual aspects of health care provided by their primary care physician (PCP). Assessing these aspects is important to inform future primary healthcare service planning. Our objective was thus to document patients' satisfaction with and expectations from their PCP, in terms of availability and organization of their practices, and to assess whether these indicators varied across age groups and type of practice (solo, duo, group).

Methods: Cross-sectional study based on the answers to questionnaires completed by patients consulting their PCP in Geneva, Switzerland. A random sample of PCPs was asked to recruit consecutively between 50 and 100 patients coming to the practice for a scheduled medical consultation. The patients were asked to complete an anonymous questionnaire centered on their satisfaction levels and expectations towards their PCP.
\end{abstract}

Results: One thousand six hundred thirty-seven patients agreed to participate (participation rate: $97 \%$, women: $63 \%$, mean age: 54 years). Patient satisfaction was high for all the items, except for the availability of the doctor by phone and for the waiting time in the waiting room. The satisfaction rate increased with age and was higher for small practices. In relation to patients' expectations from their doctor, older patients and patients visiting larger practices tended to be more demanding.

Conclusions: Patients are generally highly satisfied with their PCP. They have a wide range of expectations which should be taken into account when considering potential improvements.

\section{Background}

Primary care physicians (PCPs) are considered in many countries as a mainstay of the medical health system. Patient satisfaction is now regarded as an important indicator of health quality alongside quality of life, mortality and health costs $[1,2]$ and is of growing interest to health professionals and policymakers. It is a key factor in the global assessment of health care services, because patients and doctors do not always agree on the priorities to be given to different follow up indicators $[3,4]$ and patients' satisfaction may influence their health status and medical costs [5]. The assessment of health care services using patients' satisfaction is generally well accepted by

\footnotetext{
* Correspondence: paulsebo@hotmail.com

'Primary Care Unit, Faculty of medicine, University of Geneva, Geneva, Switzerland

Full list of author information is available at the end of the article
}

PCPs [2]. Negative evaluations by their patients should lead doctors to reflect upon their practice in order to better respond to their patients' expectations.

A European task force recently developed a standardized questionnaire, validated in French, in order to assess patient satisfaction in primary care, the Europep project (EUROpean task force on Patient Evaluation of general Practice) [6-8]. The questionnaire includes 23 questions assessing five dimensions of the patient-doctor relationship: relationship and communication, health care services, information and support, availability and access, organization. The satisfaction level is assessed for each question through a 5 points scale from poor to excellent. Several authors have used this questionnaire to assess patients' satisfaction with medical health care services in primary care $[7,9-12]$. These studies consistently showed a high degree of satisfaction among patients. 
Primary care is experiencing new developments, mainly in terms of practice organization. Though a trend towards larger practices is currently noted in most high income countries, several studies have shown that patients seem to prefer small practices [9, 11, 13-18]. This finding could be explained by the fact that patients from small practices tend to report better accessibility of care, higher performance of receptionists and better continuity of care in the doctor-patient relationship [14]. However, defining the optimal size of practice is probably difficult, as small practices tend to show reduced quality performance [14].

To our knowledge, no study has at the same time assessed patients' satisfaction and their expectations concerning the organizational and contextual aspects of health care provided by their PCP. Assessing these aspects is important to inform future primary healthcare service planning. Our objective was thus to document patients' satisfaction with and expectations from their PCP, in terms of availability and organization of their practices, and to assess whether these indicators varied across age groups ( $<25$ years, 25-65 years, > 65 years) and type of practice (solo, duo, group).

\section{Methods}

\section{Recruitment of the doctors and the patients}

This cross-sectional study took place in primary care practices in Geneva, Switzerland, in 2011. A random sample of 75 PCPs was selected from a sampling frame consisting of all the PCPs practising in the canton and members of the professional organisation of Genevabased physicians. They were invited to participate by post, in order to include 25 PCPs in the study (expected participation rate: $33 \%$ ). In the absence of any response, the doctors were personally contacted by phone two or three weeks later.

\section{Data collection}

A research assistant contacted each participating doctor's medical assistant to inform them about the practical procedures for the study data collection. They were asked to recruit between 50 and 100 consecutive patients coming to the practice for a planned consultation. Patients were given oral and written information and, following written consent, were asked to complete a questionnaire containing general questions (age, sex, nationality, marital status, education, work status, health status) and questions about their satisfaction with and expectations from their PCP.

Patients' satisfaction was assessed using six questions from the Europep questionnaire, validated in French, and scored on a 5 point Likert scale ranging from "poor" to "excellent": helpfulness of staff, getting an appointment to suit the patient, getting through to the practice on the telephone, being able to speak to the doctor on the telephone, waiting time in the waiting room and providing quick services for urgent health problems [8]. Note that we included in the questionnaire only these six items regarding availability and access, because we were interested in assessing organizational aspects of health care provided by the PCPs.

Patients' expectations were addressed using fifteen items: five items exploring accessibility and availability (waiting time deemed acceptable in the waiting room, waiting time deemed acceptable to get an appointment for urgent/non urgent health problems, to be able to speak to the PCP on the telephone, number of interruptions of the consultation related to phone calls deemed acceptable), two items regarding equipment (importance of having a laboratory/a X-ray equipment in the practice), three items exploring appearance and cleanliness (importance of wearing a white coat during the consultation, importance that the doctor washed his/her hands, importance of the cleanliness of the practice), and finally five items regarding accessibility and availability outside office opening hours (importance that the PCP is accessible by phone $24 \mathrm{~h}$ a day/the week-end during the day, importance that the PCP makes home visits/makes home visits $24 \mathrm{~h}$ a day/24 $\mathrm{h}$ the week-end during the day). These issues, identified through a review of the literature and discussion between the members of the research team, were selected as they were considered as the most important expectations to be studied. The questions concerning the importance given to equipment, appearance/cleanliness and accessibility/availability were assessed on a 5 point Likert scale ranging from "not at all important" to "extremely important".

The questionnaire was pretested in a PCP's practice (PS) and feedback was obtained from the respondents $(n=20)$, in order to estimate the mean time needed to complete the questionnaire and to identify any difficulties patients may meet in responding to the questions. The questionnaire was then modified accordingly. Finally, we pretested the new version of the questionnaire $(n=10)$. We also re-administered the same questionnaire to a small number of patients $(n=5)$ at 2 weeks interval to make sure the questionnaire was reliable in time.

Eligibility criteria were an age older than 15 years, understanding and writing French and having a planned appointment with the doctor; all the new patients and those suffering from disorders affecting their ability to consent were excluded. The self-administered anonymous questionnaire had to be completed in the waiting room of the practice, before or after the consultation, and deposited at the desk in a closed box. The research protocol was approved by the ethics committee for research in ambulatory care in Geneva (reference: 09-01). 


\section{Sample size justification and statistical analysis}

The sample size was estimated in order to measure the prevalence $(50 \%)$ of the "patient expectations » items (categorical data) with a margin of error inferior to $5 \%$. A sample size of 400 patients would have been sufficient, but we had to take the cluster effect into account, related to the fact that the patients were recruited in different practices (adjustment for taking into account the artificial decrease of the variance of measures collected in the same practice). Using an intra-class correlation of 0.025 (estimate based on published data and our personal experience), [19] and the assumption that 100 patients could be recruited in each practice, the inflation factor was 3.48 and our estimated total sample size was 1392 patients (400*3.48). In order to limit the PCPs' workload for our study, we asked them to enroll between 50 and 100 patients during the study period. Thus, the number of PCPs needed was estimated to be between 14 and 28, leading to an average number of 21 , which we rounded up to 25 to take into account possible withdrawals from the study.

Frequencies were used to describe binary and categorical variables, and means for continuous variables. For the items assessing satisfaction levels, we used the percentage of patients being satisfied or very satisfied (4 or $5 / 5$ on the Likert satisfaction scale), as well as the mean score. We computed satisfaction levels in two different ways: we recorded the percentage of patients being satisfied or very satisfied (dichotomous variable), because this outcome was often reported in previous studies, as well as the mean score (continuous variable), because the additional information it contained might improve efficiency. The items assessing expectations were presented as categorical data or means, where appropriate. Subgroup analyses were undertaken for age groups $(<25$ years, $25-$ 65 years and $>65$ years) and type of practice (solo, duo and group). For categorical data, we used Chi-squared tests to compare the frequencies obtained in each subgroup and conditional logistic regression to simultaneously adjust for other doctor and patient characteristics. For numerical data, we used one-way analysis of variance to compare the means in each subgroup and linear regression to control for confounding factors.

\section{Results}

Among the 75 PCPs located in the Geneva area who were contacted at random, $31 \%(n=23)$ agreed to participate in the study (men: $61 \%$, mean age: 50 years), corresponding to $92 \%$ of the expected number of participants. Twenty $(87 \%)$ were certified in general internal medicine, twelve (52 \%) had their medical office located in a city (i.e. with a population greater than $15^{\prime} 000$ ); the majority had solo or duo practices (39\% and $35 \%$ ), and almost two thirds employed medical assistants or administrative staff. On average, they were working 38.6 hours per week (SD 11.1), 4.7 days per week (SD 0.6), and were relatively experienced doctors (average number of working-years since certification: 10.5 (SD 10.1), average number of working-years in the current medical practice: 8.6 (SD 8.6). It is worth noting that the sample of 23 PCPs who agreed to participate seems to be representative of the study population $(n=650)$, as mean age (50 vs. 53 years) and sex (men: $61 \%$ in the two groups) are similar.

One thousand six hundred thirty-seven patients provided consent to participate in the study, corresponding to 71 patients per doctor on average, well above the expected sample size $(n=1392)$. Only 45 patients refused to participate (women: $60 \%$, mean age: 64 years), the resulting participation rate being above $97 \%$.

Table 1 presents the patients' socio-demographic characteristics. They were predominantly women (63\%), aged 54 on average (SD 18 years). They were divided into three subgroups according to their age: $6 \%$ were under 25, $62 \%$ between 25 and 65, and $32 \%$ over 65 . Half the patients were married, and three quarters were Swiss. Almost one third completed a university training or equivalent, and more than half had education beyond intermediate school. The majority had a professional activity (41 \%) or was retired (30\%). Only $18 \%$ rated their health as moderate or poor. Finally, the overall satisfaction level was judged excellent, since more than $95 \%$ of the patients were very satisfied (i.e. having rated 4 or $5 / 5$ on the Likert scale).

Table 2 shows the satisfaction levels according to the three age groups, presented in two different ways: the \% of patients very satisfied (i.e. having rated 4 or $5 / 5$ ) and the mean score (SD). The vast majority of the patients were very satisfied, mainly concerning the overall satisfaction and the helpfulness of staff. However two items, the possibility to speak to the doctor by phone, and above all, the waiting time in the waiting room, were rated less favorably by the patients. Moreover, the satisfaction levels increased with age, regardless of the domain assessed ( $p$-value for linear trend $<0.05$ for all the items), though the association between age group and satisfaction items disappeared in multivariate analyses, except for being able to speak to the PCP on the telephone ( $p$-value 0.02 for the dichotomous variable) and for providing quick services for urgent health services ( $p$-value 0.02 for mean score).

Table 3 presents patients' satisfaction according to the type of practice. The satisfaction levels decreased with a higher number of PCPs in the practice, except for overall satisfaction, which showed similar ratings in the three types of practices, and satisfaction concerning the ability to speak to the doctor, which was highest for duo practices. In multivariate analyses, the differences in 
Table 1 Patients' socio-demographic characteristics $(n=1637)$

\begin{tabular}{|c|c|c|}
\hline Characteristics & $n / N^{a}$ & Percer \\
\hline Female & $981 / 1563$ & 62.8 \\
\hline \multicolumn{3}{|l|}{ Age group } \\
\hline$<25$ years & $97 / 1566$ & 6.2 \\
\hline $25-65$ years & $974 / 1566$ & 62.2 \\
\hline$>65$ years & $495 / 1566$ & 31.6 \\
\hline \multicolumn{3}{|l|}{ Marital status } \\
\hline Single & $386 / 1579$ & 24.4 \\
\hline Married & 783/1579 & 49.6 \\
\hline Divorced or separated & $276 / 1579$ & 17.5 \\
\hline Widowed & $134 / 1579$ & 8.5 \\
\hline \multicolumn{3}{|l|}{ Nationality } \\
\hline Swiss & $1163 / 1569$ & 74.1 \\
\hline Italian & $92 / 1569$ & 5.9 \\
\hline French & $89 / 1569$ & 5.7 \\
\hline Portuguese & $57 / 1569$ & 3.6 \\
\hline Spanish & $34 / 1569$ & 2.2 \\
\hline Other (<2 \%) & $134 / 1569$ & 8.5 \\
\hline \multicolumn{3}{|l|}{ Completed training } \\
\hline No training & $63 / 1505$ & 4.2 \\
\hline Compulsory schooling & $149 / 1505$ & 9.9 \\
\hline Apprenticeship & $506 / 1505$ & 33.6 \\
\hline $\begin{array}{l}\text { Baccalaureate or diploma from intermediate } \\
\text { school }\end{array}$ & $340 / 1505$ & 22.6 \\
\hline University, $\mathrm{FIT}^{\mathrm{b}}, \mathrm{UAS}^{\mathrm{b}}$ & $447 / 1505$ & 29.7 \\
\hline \multicolumn{3}{|l|}{ Work status } \\
\hline Student & $85 / 1569$ & 5.4 \\
\hline Occupational activity & $648 / 1569$ & 41.3 \\
\hline Retired & $467 / 1569$ & 29.8 \\
\hline $\begin{array}{l}\text { Recipient of unemployment or invalidity } \\
\text { insurance }\end{array}$ & $133 / 1569$ & 8.4 \\
\hline $\begin{array}{l}\text { Other (mainly house-wife/husband and without } \\
\text { employment) }\end{array}$ & 236/1569 & 15.1 \\
\hline \multicolumn{3}{|l|}{ General health status } \\
\hline Excellent or very good & $449 / 1571$ & 28.6 \\
\hline Good & $848 / 1571$ & 54.0 \\
\hline Moderate or poor & $274 / 1571$ & 17.5 \\
\hline \multicolumn{3}{|l|}{ Number of consultations in the last 6 months } \\
\hline $1-2$ & $676 / 1571$ & 43.0 \\
\hline $3-4$ & $491 / 1571$ & 31.3 \\
\hline $5-6$ & 266/1571 & 16.9 \\
\hline$\geq 7$ & 138/1571 & 8.8 \\
\hline \multicolumn{3}{|l|}{ Overall satisfaction level with the medical office } \\
\hline 1 (very low) & $2 / 1584$ & 0.1 \\
\hline 2 & $8 / 1584$ & 0.5 \\
\hline
\end{tabular}

Table 1 Patients' socio-demographic characteristics $(n=1637)$ (Continued)

\begin{tabular}{lll}
\hline 3 & $58 / 1584$ & 3.7 \\
4 & $438 / 1584$ & 27.7 \\
5 (excellent) & $1078 / 1584$ & 68.1 \\
\hline
\end{tabular}

${ }^{a}$ FIT Federal Institute of Technology, UAS = University of Applied Sciences

${ }^{\mathrm{b}}$ The number of missing values per item varied from 53 to 132

satisfaction between the three practice types remained statistically significant regarding helpfulness of the staff (for the dichotomous variable), getting through to the practice on the telephone, waiting time in the waiting room and providing quick services for urgent health problems.

Table 4 shows patients' expectations according to the three age groups. The younger patients were slightly more demanding in terms of waiting time in the waiting room, but less in terms of waiting period to obtain an appointment for urgent health problems. There was no age group difference for health problems viewed as non urgent by the patients, since the vast majority considered a waiting period of 5 days to two weeks as being acceptable. Many responders found it important to be able to speak to the doctor in the day, but the older patients were a little more demanding on this issue. Approximately two thirds, regardless of the age group, found acceptable that the doctor interrupt the consultation, once, because of phone calls. The laboratory and/or X-ray equipment were judged as being relatively important, mainly for the patients visiting the equipped medical offices. In addition, the older the patients visiting the equipped or non-equipped practices were, the more they considered the equipment important or not important respectively. Overall, wearing the white coat was judged less important. The same trend was seen again with increasing age, between the patients who consulted doctors wearing the white coat, and those who did not wear it. By contrast, two items, hand washing by the doctor and cleanliness of the practice, were a priority concern for all patients. Finally, neither having access to the doctor on the telephone 24 hours a day or on week-ends, nor receiving home visits, were judged as fundamental, but the older patients were a little more demanding on these issues. The association between age group and expectation items decreased in multivariate analyses, except for cleanliness of the practice, but remained statistically significant for several items (importance of wearing a white coat, importance that the PCP is accessible by phone 24 hours a day and makes home visits, importance of having X-ray for patients consulting unequipped PCPs).

Table 5 presents patients' expectations according to the type of practice. The patients visiting group practices were slightly more demanding in terms of waiting period 
Table 2 Patients' satisfaction levels with the primary care physicians (PCPs) and their practices, according to patients' age group

\begin{tabular}{|c|c|c|c|c|c|}
\hline Characteristics & $<25 y$ & $25-65 y$ & $>65 y$ & Crude $p$-value & Adjusted $p$-value ${ }^{a}$ \\
\hline \multicolumn{6}{|l|}{ Overall satisfaction level } \\
\hline Very high to excellent satisfaction level, \% & 94.8 & 95.2 & 97.5 & 0.10 & 0.71 \\
\hline Mean satisfaction score (SD) & $4.5(0.6)$ & $4.6(0.6)$ & $4.7(0.5)$ & $<0.001^{*}$ & 0.05 \\
\hline \multicolumn{6}{|l|}{ Helpfulness of the staff (other than the PCP) } \\
\hline Very high to excellent satisfaction level, \% & 90.7 & 94.4 & 97.5 & 0.01 & 0.74 \\
\hline Mean satisfaction score (SD) & $4.5(0.7)$ & $4.7(0.6)$ & $4.8(0.5)$ & $<0.001^{*}$ & 0.15 \\
\hline \multicolumn{6}{|l|}{ Getting an appointment to suit the patient } \\
\hline Very high to excellent satisfaction level, \% & 87.6 & 91.2 & 95.0 & 0.01 & 0.92 \\
\hline Mean satisfaction score (SD) & $4.3(0.8)$ & $4.5(0.8)$ & $4.7(0.6)$ & $<0.001^{*}$ & 0.42 \\
\hline \multicolumn{6}{|l|}{ Getting through to the practice on the telephone } \\
\hline Very high to excellent satisfaction level, \% & 89.7 & 89.1 & 92.2 & 0.18 & 0.96 \\
\hline Mean satisfaction score (SD) & $4.4(0.7)$ & $4.4(0.8)$ & $4.6(0.7)$ & $0.002^{*}$ & 0.43 \\
\hline \multicolumn{6}{|l|}{ Being able to speak to the PCP on the telephone } \\
\hline Very high to excellent satisfaction level, \% & 66.7 & 79.7 & 88.2 & $<0.001$ & 0.02 \\
\hline Mean satisfaction score (SD) & $3.9(1.0)$ & $4.2(0.9)$ & $4.4(0.9)$ & $<0.001^{*}$ & 0.07 \\
\hline \multicolumn{6}{|l|}{ Waiting time in the waiting room } \\
\hline Very high to excellent satisfaction level, \% & 56.7 & 75.5 & 80.6 & $<0.001$ & 0.69 \\
\hline Mean satisfaction score (SD) & $3.7(1.0)$ & $4.0(0.9)$ & $4.1(0.9)$ & $<0.001^{*}$ & 0.67 \\
\hline \multicolumn{6}{|c|}{ Providing quick services for urgent health problems } \\
\hline Very high to excellent satisfaction level, \% & 78.3 & 90.0 & 93.7 & $<0.001$ & 0.20 \\
\hline Mean satisfaction score (SD) & $4.3(0.9)$ & $4.5(0.7)$ & $4.6(0.7)$ & $<0.001^{*}$ & 0.02 \\
\hline
\end{tabular}

${ }^{*} p$-value for linear trend $<0.001$

adjusted for all doctor and patient variables listed in Table 6

to obtain an appointment, though the difference was statistically significant only for urgent health problems. They were also more likely to expect to be able to speak to the PCP on the telephone, and were more demanding in terms of equipment (laboratory and X-ray). The patients' views regarding waiting time in the waiting room, hand washing and cleanliness of the practice, which were a priority concern for all the patients, doctor's attire, doctor's accessibility by phone outside practice hours and home visits, appeared to be relatively similar between the different practice types, although in univariate analyses some differences were statistically significant. In multivariate analyses the association with type of practice decreased for the vast majority of expectation items. However, there were statistically significant differences between practice types for waiting time in the waiting room and to get an appointment for urgent health problems (patients in solo practices expect to wait less time in the waiting room but longer to get an urgent appointment), white coat (patients in solo practices are more likely to prefer their doctor wearing a white coat in practices in which the doctor is wearing one, and more likely not to prefer this in practices in which the doctor does not wear a white coat), hand washing and home visits, as well as for importance of having a laboratory and X-ray facility for patients consulting unequipped PCPs.

Finally, Table 6 presents PCPs' and patients' characteristics which are simultaneously associated with the overall satisfaction level in multivariate analysis. The patients consulting uncertified doctors were less satisfied than those consulting certified doctors, when taking the other variables into account (OR 0.2, $95 \%$ CI 0.1-0.6, $p$-value $0.003)$. The other characteristics were not associated with the overall satisfaction level in multivariate analyses.

\section{Discussion}

Our study showed high patient satisfaction levels with organizational aspects of care, except regarding the possibility to speak to the doctor by phone and the waiting time in the waiting room, which were less well rated. The satisfaction ratings tended to increase with age but decrease with a higher number of PCPs in the practice. Only doctors' certification status (specialist title holder or not) was associated with overall satisfaction in multivariate analyses.

Several studies used the questionnaire developed by the Europep project (EUROpean task force on Patient Evaluation of general Practice) to assess patients' satisfaction with medical health care services in primary care. 
Table 3 Patients' satisfaction levels with the primary care physicians (PCPS) and their practices, according to type of practice

\begin{tabular}{|c|c|c|c|c|c|}
\hline Characteristics & Solo & Duo & Group & Crude $p$-value & Adjusted $p$-value ${ }^{a}$ \\
\hline \multicolumn{6}{|l|}{ Overall satisfaction level } \\
\hline Very high to excellent satisfaction level, \% & 95.3 & 96.4 & 95.2 & 0.54 & 0.48 \\
\hline Mean satisfaction score (SD) & $4.6(0.6)$ & $4.7(0.6)$ & $4.6(0.6)$ & 0.04 & 0.87 \\
\hline \multicolumn{6}{|l|}{ Helpfulness of the staff (other than the PCP) } \\
\hline Very high to excellent satisfaction level, \% & 96.5 & 96.0 & 92.6 & 0.01 & 0.02 \\
\hline Mean satisfaction score (SD) & $4.7(0.6)$ & $4.7(0.6)$ & $4.6(0.7)$ & $<0.001^{*}$ & 0.15 \\
\hline \multicolumn{6}{|l|}{ Getting an appointment to suit the patient } \\
\hline Very high to excellent satisfaction level, \% & 94.8 & 93.9 & 87.9 & $<0.001$ & 0.42 \\
\hline Mean satisfaction score (SD) & $4.6(0.6)$ & $4.6(0.7)$ & $4.4(0.9)$ & $<0.001^{*}$ & 0.35 \\
\hline \multicolumn{6}{|c|}{ Getting through to the practice on the telephone } \\
\hline Very high to excellent satisfaction level, $\%$ & 93.3 & 90.5 & 86.9 & 0.004 & 0.03 \\
\hline Mean satisfaction score (SD) & $4.6(0.7)$ & $4.5(0.7)$ & $4.4(0.8)$ & $0.003^{* *}$ & 0.02 \\
\hline \multicolumn{6}{|l|}{ Being able to speak to the PCP on the telephone } \\
\hline Very high to excellent satisfaction level, \% & 83.6 & 87.0 & 73.3 & $<0.001$ & 0.50 \\
\hline Mean satisfaction score (SD) & $4.3(0.9)$ & $4.3(0.8)$ & $4.0(1.1)$ & $<0.001^{*}$ & 0.72 \\
\hline \multicolumn{6}{|l|}{ Waiting time in the waiting room } \\
\hline Very high to excellent satisfaction level, \% & 81.9 & 76.4 & 71.2 & 0.001 & $<0.001$ \\
\hline Mean satisfaction score (SD) & $4.2(1.0)$ & $4.0(0.9)$ & $3.9(1.0)$ & $<0.001^{*}$ & 0.003 \\
\hline \multicolumn{6}{|c|}{ Providing quick services for urgent health problems } \\
\hline Very high to excellent satisfaction level, \% & 94.9 & 91.5 & 85.1 & $<0.001$ & $<0.001$ \\
\hline Mean satisfaction score (SD) & $4.6(0.7)$ & $4.6(0.7)$ & $4.4(0.9)$ & $<0.001^{*}$ & 0.02 \\
\hline
\end{tabular}

${ }^{*} p$-value for linear trend $<0.001,{ }^{* *} p$-value for linear trend $<0.05$ and $\geq 0.001$

adjusted for all doctor and patient variables listed in Table 6

The results of these studies compare favorably with our own results. An international survey (ten countries including Switzerland, $>1000$ patients/country) showed a high degree of satisfaction among patients, especially in Switzerland, Germany and Belgium [7, 9]. A study carried out in Belgium ( $N=994$ patients, $42 \mathrm{PCPs})$ confirmed these results with more than $80 \%$ of participants having rated 4 or $5 / 5$ on the satisfaction scale for the great majority of the items [12]. In this study, questions about accessibility and availability were rated slightly less favorably, mainly helpfulness of the staff ( $79 \%$ of the responders were satisfied or very satisfied) and the waiting time in the waiting room (60\%). Finally, according to a Slovenian study ( $n=1809$ patients, 36 PCPs) more than $80 \%$ of the participants judged medical health care services very favorably [10]. Again, the lowest rating was given to the waiting time, since only approximately $60 \%$ were satisfied or very satisfied. Although understandably many patients do not like to spend too much time in the doctors' waiting room, this inconvenience seems less important to the patients than the free choice of doctor or appointment $[20,21]$. In addition, time spent with the doctor seems a better predictor of the patients' overall satisfaction than the waiting time spent in the waiting room [22]. In other words, the negative association between waiting time and patient satisfaction was found to be moderated by time spent with the doctor. As a result, the worst scenario was the combination of long waiting time and short visit time.

As seen in prior studies, [7, 10, 12, 17, 23, 24] we found that increased age was associated with improved satisfaction. It was hypothesized that older patients could receive more respect, consideration and attention from their PCPs and that they could be more reluctant to criticize them due to a strong doctor-patient relationship built up over the years [12]. Interestingly, whereas older patients reported higher satisfaction ratings, our study showed that they were also more demanding, suggesting, in spite of this, that their PCPs have met their expectations.

The place of primary care in the healthcare system is currently changing in many high income countries, including Switzerland, with a trend towards having larger practices with more staff. However, our results support previous studies, which have shown that patients seem to prefer small practices $[9,11,13-18]$. This finding could be explained by the fact that patients from small practices report better accessibility of care, higher performance of receptionists and better continuity of care in the doctorpatient relationship [14]. Another explanation may be that 
Table 4 Patients' expectations towards the primary care physicians (PCPs) and their practices, according to patients' age group

\begin{tabular}{|c|c|c|c|c|c|}
\hline Characteristics & $<25 y$ & $25-65 y$ & $>65 y$ & Crude $p$-value & Adjusted $p$-value \\
\hline \multicolumn{6}{|l|}{ Waiting time deemed acceptable } \\
\hline In the waiting room (\%) & & & & 0.01 & 0.18 \\
\hline$\leq 10 \min$ & 40.6 & 26.7 & 27.6 & & \\
\hline $15 \min$ & 34.4 & 42.0 & 37.8 & & \\
\hline $20 \mathrm{~min}$ & 7.3 & 10.3 & 13.6 & & \\
\hline $25 \min$ & 4.2 & 0.9 & 1.7 & & \\
\hline $30 \mathrm{~min}$ & 10.4 & 16.6 & 16.3 & & \\
\hline$\geq 35 \min$ & 3.1 & 3.5 & 3.1 & & \\
\hline To get an appointment for non urgent health problems (\%) & & & & 0.09 & 0.69 \\
\hline In the day & 2.1 & 6.9 & 9.3 & & \\
\hline $1-2$ days & 14.6 & 11.5 & 9.3 & & \\
\hline $3-4$ days & 20.8 & 17.3 & 14.4 & & \\
\hline $5-7$ days & 31.3 & 25.4 & 24.4 & & \\
\hline $1-2$ weeks & 20.8 & 25.7 & 27.3 & & \\
\hline$>2$ weeks & 10.4 & 13.2 & 15.3 & & \\
\hline To get an appointment for urgent health problems (\%) & & & & 0.01 & 0.30 \\
\hline$<1 \mathrm{~h}$ & 8.3 & 7.2 & 13.1 & & \\
\hline In the day & 48.5 & 53.7 & 48.4 & & \\
\hline $1-2$ days & 33.0 & 33.3 & 31.0 & & \\
\hline$\geq 3$ days & 10.3 & 5.8 & 7.5 & & \\
\hline To be able to speak to the PCP on the telephone (\%) & & & & $<0.001$ & 0.06 \\
\hline No waiting time & 7.3 & 6.9 & 13.8 & & \\
\hline$<1 \mathrm{~h}$ & 17.7 & 15.5 & 24.1 & & \\
\hline In the day & 57.3 & 58.2 & 49.5 & & \\
\hline 1 day & 11.5 & 14.3 & 8.5 & & \\
\hline$\geq 2$ days & 6.3 & 5.2 & 4.2 & & \\
\hline $\begin{array}{l}\text { Number of interruptions of the consultation related to phone calls } \\
\text { deemed acceptable (\%) }\end{array}$ & & & & $<0.001$ & 0.81 \\
\hline 0 & 9.3 & 13.9 & 5.6 & & \\
\hline 1 & 66.0 & 63.7 & 65.8 & & \\
\hline$\geq 2$ & 24.7 & 22.4 & 28.6 & & \\
\hline \multicolumn{6}{|l|}{$\begin{array}{l}\text { Importance of having a laboratory in the } \\
\text { practice (mean (SD)) }\end{array}$} \\
\hline Patients consulting PCP with a laboratory & $3.2(1.2)$ & $3.6(1.5)$ & $4.0(1.3)$ & $<0.001^{*}$ & 0.30 \\
\hline Patients consulting PCP without a laboratory & $3.1(1.2)$ & $2.9(1.6)$ & $2.8(1.7)$ & 0.78 & 0.87 \\
\hline All the patients & $3.2(1.2)$ & $3.4(1.5)$ & $3.8(1.5)$ & $<0.001^{*}$ & 0.40 \\
\hline \multicolumn{6}{|l|}{ Importance of having $x$-ray equipment in the practice (mean (SD)) } \\
\hline Patients consulting PCP with $x$-ray equipment & $3.5(1.1)$ & $3.7(1.4)$ & $4.0(1.4)$ & $0.05^{* *}$ & 0.43 \\
\hline Patients consulting PCP without $x$-ray equipment & $2.8(1.3)$ & $2.2(1.4)$ & $2.1(1.5)$ & $0.01^{* *}$ & 0.03 \\
\hline All the patients & $3.1(1.2)$ & $2.8(1.5)$ & $2.8(1.7)$ & 0.07 & 0.10 \\
\hline \multicolumn{6}{|l|}{ Importance of wearing a white coat during the consultation (mean (SD)) } \\
\hline Patients consulting PCP wearing a white coat & $2.6(1.5)$ & $2.8(1.6)$ & $3.1(1.7)$ & $0.001^{*}$ & 0.03 \\
\hline Patients consulting PCP not wearing a white coat & $2.2(1.4)$ & $2.0(1.4)$ & $1.9(1.4)$ & 0.50 & 0.32 \\
\hline All the patients & $2.4(1.5)$ & $2.5(1.6)$ & $2.8(1.7)$ & $0.01^{* *}$ & 0.04 \\
\hline Importance of washing his hands (mean (SD)) & $4.7(0.7)$ & $4.6(0.9)$ & $4.5(1.0)$ & 0.17 & 0.29 \\
\hline
\end{tabular}


Table 4 Patients' expectations towards the primary care physicians (PCPs) and their practices, according to patients' age group (Continued)

\begin{tabular}{|c|c|c|c|c|c|}
\hline Importance of the cleanliness of the practice (mean (SD)) & $4.5(0.8)$ & $4.6(0.8)$ & $4.7(0.7)$ & $0.04^{* *}$ & 0.01 \\
\hline \multicolumn{6}{|c|}{ Importance that the PCP is accessible by phone $24 \mathrm{~h}$ a day (mean (SD)) } \\
\hline Patients consulting PCP accessible $24 \mathrm{~h}$ a day & $2.1(1.2)$ & $2.1(1.3)$ & $2.5(1.5)$ & 0.03 & 0.10 \\
\hline Patients consulting PCP not accessible $24 \mathrm{~h}$ a day & $2.2(1.2)$ & $2.1(1.3)$ & $2.3(1.5)$ & 0.05 & 0.09 \\
\hline All the patients & $2.2(1.2)$ & $2.1(1.3)$ & $2.4(1.5)$ & $0.002^{* *}$ & 0.02 \\
\hline \multicolumn{6}{|c|}{$\begin{array}{l}\text { Importance that the PCP is accessible by phone the week-end during the } \\
\text { day (mean (SD) }\end{array}$} \\
\hline Patients consulting PCP accessible $24 \mathrm{~h}$ a day & $2.4(1.1)$ & $2.1(1.3)$ & $2.3(1.5)$ & 0.05 & 0.34 \\
\hline Patients consulting PCP not accessible $24 \mathrm{~h}$ a day & $2.2(1.2)$ & $2.0(1.3)$ & $2.1(1.4)$ & 0.52 & 0.19 \\
\hline All the patients & $2.3(1.1)$ & $2.0(1.3)$ & $2.2(1.4)$ & 0.05 & 0.10 \\
\hline \multicolumn{6}{|l|}{ Importance that the PCP makes home visits (mean (SD)) } \\
\hline Patients consulting PCP accessible $24 \mathrm{~h}$ a day & $2.2(1.3)$ & $2.9(1.4)$ & $3.5(1.4)$ & $<0.001^{*}$ & 0.01 \\
\hline Patients consulting PCP not accessible $24 \mathrm{~h}$ a day & $2.4(1.3)$ & $2.3(1.3)$ & $3.1(1.6)$ & $<0.001^{*}$ & 0.65 \\
\hline All the patients & $2.3(1.3)$ & $2.7(1.4)$ & $3.4(1.5)$ & $<0.001^{*}$ & 0.02 \\
\hline \multicolumn{6}{|c|}{ Importance that the PCP makes home visits $24 \mathrm{~h}$ a day (mean (SD)) } \\
\hline Patients consulting PCP accessible $24 \mathrm{~h}$ a day & $1.6(1.0)$ & $2.6(1.5)$ & $2.6(1.5)$ & 0.10 & 0.56 \\
\hline Patients consulting PCP not accessible $24 \mathrm{~h}$ a day & $1.7(1.1)$ & $1.6(1.0)$ & $1.8(1.3)$ & 0.001 & 0.33 \\
\hline All the patients & $1.7(1.1)$ & $1.7(1.1)$ & $1.9(1.3)$ & 0.01 & 0.18 \\
\hline \multicolumn{6}{|c|}{$\begin{array}{l}\text { Importance that the PCP makes home visits } 24 \mathrm{~h} \text { the week-end during } \\
\text { the day (mean (SD) }\end{array}$} \\
\hline Patients consulting PCP accessible $24 \mathrm{~h}$ a day & $2.0(1.0)$ & $2.2(1.2)$ & $2.3(1.5)$ & 0.81 & 0.32 \\
\hline Patients consulting PCP not accessible $24 \mathrm{~h}$ a day & $1.9(1.1)$ & $1.7(1.1)$ & $1.8(1.3)$ & 0.20 & 0.44 \\
\hline All the patients & $1.9(1.0)$ & $1.8(1.1)$ & $1.9(1.3)$ & 0.09 & 0.40 \\
\hline
\end{tabular}

${ }^{*} p$-value for linear trend $<0.001,{ }^{* *} p$-value for linear trend $<0.05$ et $\geq 0.001$

adjusted for all doctor and patient variables listed in Table 6

patients consulting PCPs working in large practices are more demanding, as suggested by our results assessing patients' expectations. However, defining the optimal size of practice is probably difficult, as small practices tend to show reduced performance [14]. The impact on health costs, an important factor to be discussed, is not known and difficult to estimate. Larger practices may favor costs containment due to a reduction of unnecessary duplicated analyses and medical examinations, the patients' medical files being available for all partners in the practice. However, in health systems based on a fee-for-service basis reimbursement (such as in Switzerland), doctors working in large practices, which are more often equipped with laboratory and X-ray facility, could be "encouraged" to expand service volumes. What is known is the influence of practice lists (i.e. the number of patients by doctor) on health costs, larger practice lists being associated with higher per patient costs [25]. This association could again have to do with the fact that an optimized practice organization enables larger treatment volumes.

Our study also extensively assessed patients' expectations about the organizational aspects of the practice. In particular, the influence of age and practice size was explored. In summary, older patients and patients visiting larger practices tended to be more demanding, especially in terms of accessibility and availability, of professional attire (for older patients) and of equipment (for patients visiting large practices), though the association decreased for the vast majority of the items in multivariate analyses.

The finding of the influence of age on patients' expectations could be explained by the fact that elderly persons often face complex and/or chronic medical problems, require a large number of medical consultations, including emergency and/or outside office opening hours health care. Interestingly, older patients were less demanding regarding waiting time in the waiting room, probably because they were predominantly retired and, as a result, had few time constraints. In addition, we found that patients consulting PCPs working in large practices were also more demanding, which could explain why they tended to report lower satisfaction ratings. We may interpret this finding by the fact that patient expectations of solo or duo practices could be more "modest" or, in contrast, that larger health care organizations attract a specific patient population which is more demanding. 
Table 5 Patients' expectations towards the primary care physicians (PCPs) and their practices, according to type of practice

\begin{tabular}{|c|c|c|c|c|c|}
\hline Characteristics & Solo & Duo & Group & Crude $p$-value & Adjusted $p$-value \\
\hline \multicolumn{6}{|l|}{ Waiting time deemed acceptable } \\
\hline In the waiting room (\%) & & & & 0.16 & $<0.001$ \\
\hline$\leq 10 \min$ & 28.5 & 26.2 & 30.5 & & \\
\hline $15 \mathrm{~min}$ & 42.1 & 40.4 & 37.0 & & \\
\hline $20 \mathrm{~min}$ & 12.0 & 12.3 & 9.5 & & \\
\hline $25 \mathrm{~min}$ & 1.1 & 1.0 & 2.1 & & \\
\hline $30 \mathrm{~min}$ & 13.8 & 17.1 & 16.4 & & \\
\hline$\geq 35 \min$ & 2.5 & 3.0 & 4.6 & & \\
\hline To get an appointment for non urgent health problems (\%) & & & & 0.19 & 0.87 \\
\hline In the day & 7.9 & 6.4 & 9.0 & & \\
\hline $1-2$ days & 9.2 & 12.2 & 12.2 & & \\
\hline $3-4$ days & 15.1 & 17.0 & 17.5 & & \\
\hline $5-7$ days & 24.7 & 23.2 & 27.1 & & \\
\hline $1-2$ weeks & 28.5 & 26.2 & 22.7 & & \\
\hline$>2$ weeks & 14.6 & 15.0 & 11.6 & & \\
\hline To get an appointment for urgent health problems (\%) & & & & 0.01 & 0.01 \\
\hline$<1 \mathrm{~h}$ & 7.7 & 6.9 & 13.3 & & \\
\hline In the day & 51.5 & 53.6 & 48.9 & & \\
\hline $1-2$ days & 34.5 & 32.4 & 31.0 & & \\
\hline$\geq 3$ days & 6.4 & 7.1 & 6.9 & & \\
\hline To be able to speak to the PCP on the telephone (\%) & & & & 0.01 & 0.39 \\
\hline No waiting time & 9.9 & 7.9 & 10.6 & & \\
\hline$<1 \mathrm{~h}$ & 17.5 & 16.1 & 22.6 & & \\
\hline In the day & 57.5 & 57.8 & 48.7 & & \\
\hline 1 day & 12.0 & 11.8 & 13.7 & & \\
\hline$\geq 2$ days & 3.2 & 6.4 & 4.4 & & \\
\hline $\begin{array}{l}\text { Number of interruptions of the consultation related to phone } \\
\text { calls deemed acceptable (\%) }\end{array}$ & & & & 0.01 & 0.71 \\
\hline 0 & 9.3 & 11.3 & 11.7 & & \\
\hline 1 & 65.0 & 68.1 & 59.1 & & \\
\hline$\geq 2$ & 25.7 & 20.6 & 29.2 & & \\
\hline \multicolumn{6}{|l|}{ Importance of having a laboratory in the practice (mean (SD)) } \\
\hline Patients consulting PCP with a laboratory & $3.3(1.5)$ & $3.9(1.4)$ & $3.8(1.4)$ & $<0.001^{*}$ & 0.21 \\
\hline Patients consulting PCP without a laboratory & $3.5(0.9)$ & $2.5(1.5)$ & $3.9(1.3)$ & $<0.001^{*}$ & 0.01 \\
\hline All the patients & $3.3(1.5)$ & $3.4(1.6)$ & $3.8(1.4)$ & $<0.001^{*}$ & 0.25 \\
\hline \multicolumn{6}{|l|}{ Importance of having $x$-ray equipment in the practice (mean (SD)) } \\
\hline Patients consulting PCP with $x$-ray equipment & $3.3(1.5)$ & $3.3(1.4)$ & $4.0(1.3)$ & $<0.001^{*}$ & 0.18 \\
\hline Patients consulting PCP without $\mathrm{x}$-ray equipment & $2.2(1.4)$ & $2.2(1.4)$ & $2.4(1.5)$ & 0.50 & 0.004 \\
\hline All the patients & $2.7(1.6)$ & $2.4(1.4)$ & $3.4(1.6)$ & $<0.001^{*}$ & 0.19 \\
\hline \multicolumn{6}{|c|}{ Importance of wearing a white coat during the consultation (mean (SD)) } \\
\hline Patients consulting PCP wearing a white coat & $3.1(1.7)$ & $2.8(1.6)$ & $2.8(1.6)$ & $0.02^{* *}$ & $<0.001$ \\
\hline Patients consulting PCP not wearing a white coat & $1.8(1.2)$ & $1.5(1.0)$ & $2.5(1.7)$ & $<0.001^{*}$ & $<0.001$ \\
\hline All the patients & $2.7(1.6)$ & $2.4(1.6)$ & $2.7(1.7)$ & 0.003 & 0.002 \\
\hline Importance of washing his hands (mean (SD)) & $4.7(0.8)$ & $4.6(0.9)$ & $4.5(1.0)$ & $<0.001^{*}$ & 0.01 \\
\hline
\end{tabular}


Table 5 Patients' expectations towards the primary care physicians (PCPs) and their practices, according to type of practice (Continued)

\begin{tabular}{|c|c|c|c|c|c|}
\hline Importance of the cleanliness of the practice (mean (SD)) & $4.6(0.8)$ & $4.6(0.8)$ & $4.6(0.7)$ & 0.87 & 0.10 \\
\hline \multicolumn{6}{|c|}{ Importance that the PCP is accessible by phone $24 \mathrm{~h}$ a day (mean (SD)) } \\
\hline Patients consulting PCP accessible $24 \mathrm{~h}$ a day & $2.5(1.5)$ & $2.2(1.4)$ & $2.2(1.4)$ & 0.16 & 0.03 \\
\hline Patients consulting PCP not accessible $24 \mathrm{~h}$ a day & $2.2(1.4)$ & $1.9(1.2)$ & $2.5(1.5)$ & $<0.001$ & $<0.001$ \\
\hline All the patients & $2.3(1.4)$ & $2.0(1.2)$ & $2.3(1.4)$ & $<0.001$ & 0.10 \\
\hline \multicolumn{6}{|c|}{$\begin{array}{l}\text { Importance that the PCP is accessible by phone the week-end during } \\
\text { the day (mean (SD) }\end{array}$} \\
\hline Patients consulting PCP accessible & $2.2(1.4)$ & $2.1(1.3)$ & $2.2(1.4)$ & 0.57 & 0.15 \\
\hline Patients consulting PCP not accessible & $2.2(1.3)$ & $1.9(1.2)$ & $2.3(1.4)$ & 0.002 & 0.02 \\
\hline All the patients & $2.2(1.4)$ & $1.9(1.2)$ & $2.2(1.4)$ & $<0.001$ & 0.13 \\
\hline \multicolumn{6}{|l|}{ Importance that the PCP makes home visits (mean (SD)) } \\
\hline Patients consulting PCP accessible $24 \mathrm{~h}$ a day & $3.3(1.4)$ & $2.9(1.4)$ & $3.0(1.5)$ & $0.001^{* *}$ & 0.08 \\
\hline Patients consulting PCP not accessible $24 \mathrm{~h}$ a day & $2.7(1.4)$ & $2.5(1.4)$ & $2.4(1.5)$ & 0.40 & 0.12 \\
\hline All the patients & $3.2(1.4)$ & $2.9(1.4)$ & $2.8(1.5)$ & $<0.001^{*}$ & 0.04 \\
\hline \multicolumn{6}{|c|}{ Importance that the PCP makes home visits $24 \mathrm{~h}$ a day (mean (SD)) } \\
\hline Patients consulting PCP accessible $24 \mathrm{~h}$ a day & $2.1(1.4)$ & NA & $2.5(1.5)$ & 0.40 & 0.65 \\
\hline Patients consulting PCP not accessible $24 \mathrm{~h}$ a day & $1.8(1.2)$ & $1.6(1.0)$ & $1.6(1.1)$ & $0.03^{* *}$ & 0.01 \\
\hline All the patients & $1.8(1.2)$ & $1.6(1.0)$ & $1.8(1.2)$ & 0.003 & 0.14 \\
\hline \multicolumn{6}{|c|}{$\begin{array}{l}\text { Importance that the PCP makes home visits } 24 \mathrm{~h} \text { the week-end during } \\
\text { the day (mean (SD) }\end{array}$} \\
\hline Patients consulting PCP accessible $24 \mathrm{~h}$ a day & $2.2(1.3)$ & NA & NA & NA & NA \\
\hline Patients consulting PCP not accessible $24 \mathrm{~h}$ a day & $1.8(1.2)$ & $1.7(1.1)$ & $1.9(1.2)$ & 0.02 & 0.22 \\
\hline All the patients & $1.9(1.3)$ & $1.7(1.1)$ & $1.9(1.2)$ & 0.001 & 0.04 \\
\hline
\end{tabular}

${ }^{*} p$-value for linear trend $<0.001,{ }^{* *} p$-value for linear trend $<0.05$ et $\geq 0.001$

adjusted for all doctor and patient variables listed in Table 6

We found that patients were generally more satisfied with PCPs equipped with a laboratory and/or an $\mathrm{X}$-ray facility. These results are in agreement with other studies showing higher satisfaction levels with PCPs using point-of-care laboratory testing, which is increasingly used in primary care to manage patients with chronic or emergency conditions [26, 27]. This association probably reflects the fact that attending an outside laboratory would lead to extra time, transport costs and deferred feedback of the test results [27, 28]. Note that point-of-care laboratory testing is not only logistically simpler and economically more pragmatic, but seems to lead to the same or even better therapeutic control compared to usual laboratory testing $[29,30]$. A study carried out in Switzerland confirmed its medical and economic utility, as it allowed a rapid management of the patient and avoided unnecessary additional consultations [31].

Few data are available to our knowledge about the satisfaction and/or expectations regarding management of the patients outside the office opening hours, and the studies were carried out in order to assess patients' views related to the development and implementation of centers providing medical consultations [32, 33]. These studies tend to show that patient satisfaction is lower for telephone compared to face-to-face consultations.

Another dimension of patient satisfaction deals with appearance and cleanliness (white coat, hand washing and cleanliness). The association between white coat and satisfaction tends to be weak, but results from previous studies are conflicting [34-37]. As in our study, older patients and those usually consulting PCPs wearing the white coat tend to prefer doctors wearing the coat [35, $36,38]$. In-depth discussion of the findings regarding white coat is available elsewhere [39]. Finally, our study confirmed the results of several studies showing that hand washing by the doctor and cleanliness of the practice were a priority concern for all patients [40-43].

\section{Limitations}

Since the study was carried out only in the Geneva area, our findings may not be generalizable to other regions of Switzerland and in particular to less urban and/or German or Italian speaking cantons. We excluded patients who consulted in an emergency situation or those who did not speak French. This may have introduced a selection bias 
Table 6 Adjusted associations between patients' overall satisfaction towards the primary care physicians (PCPs) and their practices, and PCPs' and patients' characteristics using conditional logistic regression

\begin{tabular}{|c|c|c|c|}
\hline Characteristics & OR & $95 \% \mathrm{Cl}$ & $p$-value \\
\hline \multicolumn{4}{|l|}{ PCPs' characteristics } \\
\hline Women & 0.8 & $0.2-2.6$ & 0.71 \\
\hline Age & 1.0 & $0.9-1.2$ & 0.82 \\
\hline No certification & 0.2 & $0.1-0.6$ & 0.003 \\
\hline Urban medical office (>15,000 people) & 0.8 & $0.3-1.9$ & 0.56 \\
\hline \multicolumn{4}{|c|}{$\begin{array}{l}\text { Number of doctors practising in the medical } \\
\text { office }\end{array}$} \\
\hline 1 & 1.0 (ref.) & & \\
\hline 2 & 1.2 & $0.4-3.3$ & 0.77 \\
\hline$\geq 3$ & 1.0 & $0.3-3.4$ & 0.98 \\
\hline \multicolumn{4}{|l|}{ Number of employees in the medical office } \\
\hline 1 & 1.0 (ref.) & & \\
\hline 2 & 1.1 & $0.3-4.8$ & 0.91 \\
\hline$\geq 3$ & 2.7 & $1.0-7.3$ & 0.05 \\
\hline Number of days worked per week & 1.2 & $0.3-4.7$ & 0.78 \\
\hline $\begin{array}{l}\text { Number of working-years since } \\
\text { certification }\end{array}$ & 1.0 & $0.9-1.1$ & 0.88 \\
\hline \multicolumn{4}{|l|}{ Patients' characteristics } \\
\hline Men & 1.0 & $0.5-1.9$ & 0.95 \\
\hline \multicolumn{4}{|l|}{ Age group } \\
\hline$<25$ years & 2.3 & $1.0-5.1$ & 0.05 \\
\hline $25-65$ years & 1.0 (ref.) & & \\
\hline$>65$ years & 1.3 & $0.2-9.4$ & 0.81 \\
\hline \multicolumn{4}{|l|}{ Marital status } \\
\hline Single & 1.1 & $0.6-2.1$ & 0.75 \\
\hline Married & 1.0 (ref.) & & \\
\hline Divorced or separated & 0.7 & $0.3-1.8$ & 0.42 \\
\hline Widowed & 1.2 & $0.3-5.9$ & 0.81 \\
\hline \multicolumn{4}{|l|}{ Nationality } \\
\hline Swiss & 1.0 (ref.) & & \\
\hline Italian & 0.8 & $0.3-2.8$ & 0.76 \\
\hline French & 1.8 & $0.3-9.7$ & 0.51 \\
\hline Portuguese & 0.6 & $0.2-2.0$ & 0.42 \\
\hline Espagnol & 1.2 & $0.2-6.8$ & 0.87 \\
\hline \multicolumn{4}{|l|}{ Completed training } \\
\hline No training & 1.6 & $0.5-5.6$ & 0.48 \\
\hline Compulsory schooling & 0.5 & $0.1-1.5$ & 0.21 \\
\hline Apprenticeship & 1.0 (ref.) & & \\
\hline $\begin{array}{l}\text { Baccalaureate or diploma from } \\
\text { intermediate school }\end{array}$ & 0.7 & $0.3-2.0$ & 0.52 \\
\hline University, $\mathrm{FIT}^{\mathrm{a}}, \mathrm{UAS}^{\mathrm{a}}$ & 1.0 & $0.3-3.0$ & 0.97 \\
\hline \multicolumn{4}{|l|}{ Work status } \\
\hline Student & 0.4 & $0.2-1.0$ & 0.05 \\
\hline
\end{tabular}

Table 6 Adjusted associations between patients' overall satisfaction towards the primary care physicians (PCPS) and their practices, and PCPs' and patients' characteristics using conditional logistic regression (Continued)

\begin{tabular}{|c|c|c|c|}
\hline Occupational activity & 1.0 (ref.) & & \\
\hline Retired & 2.7 & $0.2-30.9$ & 0.44 \\
\hline Recipient of unemployment insurance & 1.2 & $0.5-3.0$ & 0.65 \\
\hline Recipient of invalidity insurance & 1.5 & $0.5-4.3$ & 0.50 \\
\hline Excellent or very good general health status & 1.6 & $0.8-3.3$ & 0.17 \\
\hline
\end{tabular}

since these patients are likely to have lower health or socio-economic status than the patients included in the study. This "selection" is reflected in the fact that the study participants presented a relatively favorable socioeconomic status (they were predominantly Swiss, married, well-trained, working or retired, rating their health as good or excellent). However, the participation rate was high (>97\%) and patients were enrolled consecutively, thus reducing this risk of selection bias. Only $31 \%$ of the doctors who were contacted agreed to participate, which may have introduced a selection bias since these doctors may have been more concerned with their patients' level of satisfaction. The studied population is rather old as these patients are likely to consult more frequently due to their comorbidities which also increase with age. Thus, a consecutive sample will just reflect this age distribution. Finally, as the questionnaires were completed in the waiting room, patients may have been reluctant to be critical of their doctor, thus overestimating their satisfaction level. However the questionnaires were anonymous and the patients were clearly informed that their doctor would not have access to it.

\section{Conclusions}

These findings highlight the relatively high satisfaction levels with PCPs in the Geneva region, confirming the results of studies carried out in other countries. They may inform healthcare providers about the influence of age and type of practice on patients' satisfaction with and expectations from primary healthcare services. Finally, these findings are important to inform the changing primary healthcare picture as it moves away from the solo or duo model of practices, and embraces the new trend towards larger models of care.

\footnotetext{
Abbreviations

PCP: Primary care physician; PCPs: Primary care physicians; Europep: EUROpean task force on Patient Evaluation of general Practice; SD: Standard deviation; FIT: Federal Institute of Technology; UAS: University of Applied Sciences.
}

Competing interests

The authors declare that they have no competing interests. 


\section{Authors' contributions}

PS conceptualised and designed the study, organised and managed participant recruitment and data collection, contributed to data analysis and interpretation, and wrote the first draft of the paper. FH planned and carried out data analysis. PB contributed to the design and organization of the study. DH contributed to data interpretation and provided critical revision for important intellectual content. All authors read and approved the final manuscript.

\section{Acknowledgements}

We would like to warmly thank all the doctors and the patients who have accepted to participate in this study, and Florence Siltz, our research assistant, who was responsible for the organizational aspects of the project. This project was jointly funded by the Swiss Medical Association (FMH) and the Swiss Academy of Medical Sciences (ASSM).

\section{Author details}

'Primary Care Unit, Faculty of medicine, University of Geneva, Geneva, Switzerland. ${ }^{2}$ Geriatrics Division, Department of Internal Medicine, Rehabilitation and Geriatrics, Geneva University Hospitals, Geneva, Switzerland. ${ }^{3}$ Primary care practice, Lausanne, Switzerland. ${ }^{4}$ Primary Care Unit, Faculty of medicine, University of Geneva, Geneva, Switzerland. ${ }^{5}$ Department of Community, Primary Care and Emergency Medicine, Geneva University Hospitals, Geneva, Switzerland. 'Department of Pediatrics, Geneva University Hospitals, Geneva, Switzerland.

\section{Received: 1 August 2014 Accepted: 5 August 2015 Published online: 14 August 2015}

\section{References}

1. Richards T. Patients' priorities. BMJ. 1999:318:277.

2. Bovier P, Künzi B, Stalder H. Qualité des soins en médecine de premier recours: "à l'écoute de nos patients". Rev Médicale Suisse. 2006;80:2176-82.

3. Jung HP, Wensing M, Grol R. What makes a good general practitioner: do patients and doctors have different views? Br J Gen Pract J R Coll Gen Pract. 1997:47:805-9.

4. Jung HP, Wensing M, Olesen F, Grol R. Comparison of patients' and general practitioners' evaluations of general practice care. Qual Saf Health Care. 2002:11:315-9.

5. Safran DG, Montgomery JE, Chang H, Murphy J, Rogers WH. Switching doctors: predictors of voluntary disenrollment from a primary physician's practice. J Fam Pract. 2001;50:130-6.

6. Grol R, Wensing M, Mainz J, Ferreira P, Hearnshaw H, Hjortdahl P, et al. Patients' priorities with respect to general practice care: an international comparison, European Task Force on Patient Evaluations of General Practice (EUROPEP). Fam Pract. 1999;16:4-11.

7. Grol R, Wensing M, Mainz J, Jung HP, Ferreira P, Hearnshaw $H$, et al. Patients in Europe evaluate general practice care: an international comparison. Br J Gen Pract J R Coll Gen Pract. 2000;50:882-7.

8. Grol R, Wensing MJP, Kersnik J: Patients Evaluate General/family Practice: The EUROPEP Instrument. University Medical Centre; 2000.

9. Wensing M, Vedsted P, Kersnik J, Peersman W, Klingenberg A, Hearnshaw $\mathrm{H}$, et al. Patient satisfaction with availability of general practice: an international comparison. Int J Qual Health Care J Int Soc Qual Health Care ISQua. 2002;14:111-8.

10. Kersnik J. An evaluation of patient satisfaction with family practice care in Slovenia. Int J Qual Health Care J Int Soc Qual Health Care ISOua. 2000;12:143-7.

11. Heje HN, Vedsted P, Sokolowski I, Olesen F. Doctor and practice characteristics associated with differences in patient evaluations of general practice. BMC Health Serv Res. 2007;7:46.

12. Paulus D. A l'écoute des patients belges en médecine générale, Le projet EUROPEP. Louvain Med. 1999;118:S271-8.

13. Baker $\mathrm{R}$, Streatfield J. What type of general practice do patients prefer? Exploration of practice characteristics influencing patient satisfaction. Br J Gen Pract J R Coll Gen Pract. 1995:45:654-9.

14. Campbell JL, Ramsay J, Green J. Practice size: impact on consultation length, workload, and patient assessment of care. Br J Gen Pract J R Coll Gen Pract. 2001;51:644-50.

15. Glenngård $\mathrm{AH}$. Is patient satisfaction in primary care dependent on structural and organizational characteristics among providers? Findings based on data from the national patient survey in Sweden. Health Econ Policy Law. 2013;8:317-33.

16. Heje HN, Olesen F, Vedsted P. Patients' assessment of general practitioners, Association with type of practice. Ugeskr Laeger. 2010;172:1119-26.

17. Steven ID, Thomas SA, Eckerman E, Browning C, Dickens E. A patient determined general practice satisfaction questionnaire. Aust Fam Physician 1999;28:342-8

18. Wensing M, Hermsen J, Grol R, Szecsenyi J. Patient evaluations of accessibility and co-ordination in general practice in Europe. Health Expect Int J Public Particip Health Care Health Policy. 2008;11:384-90.

19. Adams G, Gulliford MC, Ukoumunne OC, Eldridge S, Chinn S, Campbell MJ. Patterns of intra-cluster correlation from primary care research to inform study design and analysis. J Clin Epidemiol. 2004;57:785-94.

20. Rubin G, Bate A, George A, Shackley P, Hall N. Preferences for access to the GP: a discrete choice experiment. Br J Gen Pract J R Coll Gen Pract. 2006;56:743-8.

21. Gerard K, Salisbury C, Street D, Pope C, Baxter H. Is fast access to general practice all that should matter? A discrete choice experiment of patients preferences. J Health Serv Res Policy. 2008:13 Suppl 2:3-10.

22. Anderson RT, Camacho FT, Balkrishnan R. Willing to wait?: the influence of patient wait time on satisfaction with primary care. BMC Health Serv Res. 2007;7:31.

23. Fan VS, Burman M, McDonell MB, Fihn SD. Continuity of care and other determinants of patient satisfaction with primary care. J Gen Intern Med. 2005;20:226-33.

24. Perneger TV, Stalder $H$, Schaller P, Raetzo MA, Etter JF. Patient satisfaction in the ambulatory setting: validation of a scale and identification of associated factors. Schweiz Med Wochenschr. 1996:126:864-71.

25. Busato A, Matter P, Künzi B, Goodman DC. Supply sensitive services in Swiss ambulatory care: an analysis of basic health insurance records for 2003-2007. BMC Health Serv Res. 2010;10:315.

26. Giuliano KK, Grant ME. Blood analysis at the point of care: issues in application for use in critically ill patients. AACN Clin Issues. 2002;13:204-20.

27. Laurence CO, Gialamas A, Bubner T, Yelland L, Willson K, Ryan P, et al. Patient satisfaction with point-of-care testing in general practice. Br J Gen Pract J R Coll Gen Pract. 2010;60:e98-104.

28. Cohen J, Piterman L, McCall LM, Segal L. Near-patient testing for serum cholesterol: attitudes of general practitioners and patients, appropriateness, and costs. Med J Aust. 1998;168:605-9.

29. Laurence C, Gialamas A, Yelland L, Bubner T, Ryan P, Willson K, et al. A pragmatic cluster randomised controlled trial to evaluate the safety, clinical effectiveness, cost effectiveness and satisfaction with point of care testing in a general practice setting - rationale, design and baseline characteristics. Trials. 2008;9:50

30. Bubner TK, Laurence CO, Gialamas A, Yelland LN, Ryan P, Willson KJ, et al. Effectiveness of point-of-care testing for therapeutic control of chronic conditions: results from the PoCT in General Practice Trial. Med J Aust. 2009;190:624-6.

31. Beeler I, Szucs T, Gutzwiller F. Is the general practice laboratory medically and economically valuable? Praxis. 2001;90:887-96.

32. Moll van Charante E, Giesen P, Mokkink H, Oort F, Grol R, Klazinga N, et al. Patient satisfaction with large-scale out-of-hours primary health care in The Netherlands: development of a postal questionnaire. Fam Pract. 2006;23:437-43.

33. Shipman C, Payne F, Hooper R, Dale J. Patient satisfaction with out-of-hours services; how do GP co-operatives compare with deputizing and practicebased arrangements? J Public Health Med. 2000;22:149-54.

34. Cha A, Hecht BR, Nelson K, Hopkins MP. Resident physician attire: does it make a difference to our patients? Am J Obstet Gynecol. 2004;190:1484-8.

35. Douse J, Derrett-Smith E, Dheda K, Dilworth JP. Should doctors wear white coats? Postgrad Med J. 2004:80:284-6.

36. Lill MM, Wilkinson TJ. Judging a book by its cover: descriptive survey of patients' preferences for doctors' appearance and mode of address. BMJ. 2005;331:1524-7

37. Rehman SU, Nietert PJ, Cope DW, Kilpatrick AO. What to wear today? Effect of doctor's attire on the trust and confidence of patients. Am J Med. 2005:118:1279-86.

38. Anvik T. Doctors in a white coat-what do patients think and what do doctors do? Scand J Prim Health Care. 1990:8:91-4.

39. Sebo P, Herrmann FR, Haller DM. White coat in primary care: what do patients think today? Cross-sectional study Swiss Med Wkly. 2014;144:W14072. 
40. Britto MT, DeVellis RF, Hornung RW, DeFriese GH, Atherton HD, Slap GB. Health care preferences and priorities of adolescents with chronic illnesses. Pediatrics. 2004;114:1272-80.

41. Ginsburg KR, Slap GB, Cnaan A, Forke CM, Balsley CM, Rouselle DM. Adolescents' perceptions of factors affecting their decisions to seek health care. JAMA J Am Med Assoc. 1995;273:1913-8.

42. Vo DX, Pate OL, Zhao H, Siu P, Ginsburg KR. Voices of Asian American youth: important characteristics of clinicians and clinical sites. Pediatrics. 2007;120:e1481-1493.

43. DeLia D, Hall A, Prinz T, Billings J. What matters to low-income patients in ambulatory care facilities? Med Care Res Rev MCRR. 2004;61:352-75.

\section{Submit your next manuscript to BioMed Central} and take full advantage of:

- Convenient online submission

- Thorough peer review

- No space constraints or color figure charges

- Immediate publication on acceptance

- Inclusion in PubMed, CAS, Scopus and Google Scholar

- Research which is freely available for redistribution 